\title{
Self-assembly of Chloro-Bridged Arene-Ruthenium Based Rectangle: Synthesis, Structural Characterization and Sensing Study
}

\author{
Sankarasekaran Shanmugaraju • Harshal Jadhav • \\ Partha Sarathi Mukherjee
}

Received: 30 October 2013/Revised: 22 January 2014 / Accepted: 28 January 2014/Published online: 4 March 2014

(C) The National Academy of Sciences, India 2014

\begin{abstract}
Self-assembly of a chloro-bridged half-sandwich $p$-cymene ruthenium(II) complex $\left[\mathrm{Ru}_{2}\left(\mu-\mathrm{Cl}_{2}\right)\left(\eta^{6}-p\right.\right.$ cymene) $\left.{ }_{2} \mathrm{Cl}_{2}\right] \mathbf{1}$ with linear ditopic donor [L; trans-1,2bis(4-pyridyl)ethylene] in presence of 2 eq. $\mathrm{AgNO}_{3}$ in $\mathrm{CH}_{3} \mathrm{CN}$ yielded a chloro-bridged molecular rectangle 2 . The rectangle $\mathbf{2}$ was isolated as nitrate salt in high yield $(90 \%)$ and characterized by infra-red, ${ }^{1} \mathrm{H}$ NMR spectroscopy including ESI-MS analyses. Molecular structure of $\mathbf{2}$ was determined by single crystal X-ray diffraction study The diffraction analysis shows that $\mathbf{2}$ adopts a tetranuclear rectangular geometry with the dimensions of $5.51 \AA \times 13.29 \AA$ and forming an infinite supramolecular chain with large internal porosity arising through multiple $\pi-\pi$ and $\mathrm{CH}-\pi$ interactions between the adjacent rectangles. Furthermore, rectangle $\mathbf{2}$ is used as selective receptor for phenolic-nitroaromatic compounds such as picric acid, dinitrophenol and nitrophenol.
\end{abstract}

Keywords Supramolecular chemistry · Self-assembly · Arene ligands $\cdot$ Ruthenium $\cdot$ X-ray crystallography

\section{Introduction}

Discrete molecular architectures of defined shapes and sizes have attracted a great deal of attention because of their intriguing structural features and potential applications [1].

Electronic supplementary material The online version of this article (doi:10.1007/s40010-014-0128-6) contains supplementary material, which is available to authorized users.

S. Shanmugaraju · H. Jadhav · P. S. Mukherjee $(\bowtie)$

Department of Inorganic and Physical Chemistry, Indian

Institute of Science, Bangalore 560 012, India

e-mail: psm@ipc.iisc.ernet.in
A plethora of multifaceted supramolecular complexes with interesting functional properties have been synthesized by this elegant synthetic strategy employing various transition metal acceptors and multidentate organic donors [2]. Platinum(II) or Palladium(II) based molecular building units have been widely used as acceptors due to their rigid squareplanar coordination geometry [3]. Recently, several shapepersistent macrocycles/cages have been constructed using arene-ruthenium based organometallic building blocks because of their structural stability and interesting properties $[4,5]$. The very first metal-ligand directed self-assembly of molecular rectangle incorporating arene-ruthenium building units was reported by Suss-Fink et al. in 1997 [6]. Since then a vast number of arene-ruthenium based molecular rectangles have been synthesized which are mostly bridged by $O, O$ - or $N, N$-chelating organic ligands and connected by linear bidentate $N$-donors [7]. But, chloro-bridged metallarectangles employing arene-ruthenium building units are not yet known because of the difficulty in pre-designing chloro-bridged arene-ruthenium acceptor having $\sim 0^{\circ}$ bite angle between their acceptor sites. Herein we report the synthesis and structural characterization of a chloro-bridged tetranuclear cationic molecular rectangle 2 incorporating $p$ cymene $\mathrm{Ru}(\mathrm{II})$ building block with 1,2-bis(4-pyridyl)ethylene (L) dipyridyl linker. Rectangle $\mathbf{2}$ shows a moderate emission characteristic in $\mathrm{CH}_{3} \mathrm{OH}$ solution and used as a macrocyclic receptor to check the binding affinity with nitroaromatic compounds. The binding affinity is described using fluorescence spectroscopic titration study. The fluorescence titration study demonstrated that rectangle $\mathbf{2}$ selectively binds with phenolic-nitroaromatic compounds such as picric acid (PA), 2,4-dinitrophenol (DNP) and 4-nitrophenol (NP) by subsequent discernable changes in the emission intensities. Notably, no such perturbation in emission intensity was observed upon titration of $\mathbf{2}$ with 
other non-phenolic nitroaromatics [1,3,5-trinitrotoluene (TNT), 2,4-dinitrotoluene (DNT), nitrobenzene (NB), nitrotoluene (NT), nitromethane (NM)]; thereby demonstrating its potential use as a selective receptor for phenolic nitroaromatics over the other nitroaromatics.

\section{Experimental}

Materials and Methods

The acceptor clip $\left[\mathrm{Ru}_{2}\left(\mu-\mathrm{Cl}_{2}\right)\left(\eta^{6}-p \text {-cymene }\right)_{2} \mathrm{Cl}_{2}\right]$ (1) was synthesized following the reported procedure [8]. trans1,2-bis(4-pyridyl)ethylene (L) was commercially purchased and used without further purification. ${ }^{1} \mathrm{H}$ NMR was studied on a Bruker $400 \mathrm{MHz}$ spectrometer. The chemical shifts $(\delta)$ are reported in ppm relative to tetramethylsilane $\left(\mathrm{Me}_{4} \mathrm{Si}\right)$ as internal standard $(0.0 \mathrm{ppm})$ or proton resonance resulting from incomplete deuteration of the NMR solvent $\mathrm{CD}_{3} \mathrm{OD}$ (3.33). IR spectra were recorded on a Bruker ALPHA FT-IR spectrometer. Electronic absorption spectral measurement was done using Perkin Elmer LAMBDA $750 \mathrm{UV} /$ visible spectrophotometer. Fluorescence titration studies were carried out on a HORIBA JOBIN-YVON Fluoromax-4-spectrometer.

Synthesis of Rectangle (2)

A mixture of $\mathrm{AgNO}_{3}(50.1 \mathrm{mg}, 0.30 \mathrm{mmol})$ and $\left[\mathrm{Ru}_{2}(\mu-\right.$ $\left.\left.\mathrm{Cl}_{2}\right)\left(\eta^{6} \text {-p-cymene }\right)_{2} \mathrm{Cl}_{2}\right](\mathbf{1} ; 91.8 \mathrm{mg}, 0.15 \mathrm{mmol})$ in $\mathrm{CH}_{3} \mathrm{CN}$ $(10 \mathrm{~mL})$ was stirred at room temperature for $3 \mathrm{~h}$, then filtered to remove $\mathrm{AgCl}$. Trans-1,2-bis(4-pyridyl)ethylene ( $\mathbf{L}$; $27.3 \mathrm{mg}, 0.15 \mathrm{mmol}$ ) was added to the filtrate and the solution was stirred at room temperature for $24 \mathrm{~h}$. The solvent was removed and the residue was extracted with acetonitrile. The filtrate was concentrated to $2 \mathrm{ml}$ and cold-diethyl ether was added to precipitate out rectangle $\mathbf{2}$ as a brownish-orange powder. Isolated yield: $90 \%$. ${ }^{1} \mathrm{H} \mathrm{NMR}\left(\mathrm{CD}_{3} \mathrm{OD}, 400 \mathrm{MHz}\right)$ :

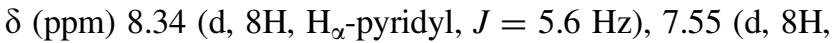
$\mathrm{H}_{\beta}$-pyridyl, $J=5.6 \mathrm{~Hz}$ ), 7.51 (s, 4H, $\mathrm{H}_{1}$-ethylene), 6.00 (d, $8 \mathrm{H}, \mathrm{H}$-cymene, $J=6.0 \mathrm{~Hz}), 5.86(\mathrm{~d}, 8 \mathrm{H}, \mathrm{H}$-cymene, $J=6.0 \mathrm{~Hz}$ ), $2.93-2.86$ (septet, $\left.4 \mathrm{H}, \mathrm{H}_{4}-\mathrm{CH}\left(\mathrm{CH}_{3}\right)_{2}\right), 2.17$ (s, $\left.12 \mathrm{H}, \mathrm{H}_{2}-\mathrm{CH}_{3}\right), 1.39$ (d, 24H, $\left.\mathrm{H}_{3}-\left(\mathrm{CH}_{3}\right)_{2} \mathrm{CH}, J=6.8 \mathrm{~Hz}\right)$. IR: $v=1,607 \mathrm{~cm}^{-1}$ corresponding to $\mathrm{C}=\mathrm{C}$ double bonds.
$\mathrm{UV} / \mathrm{Vis} \quad\left(1.0 \times 10^{-5} \mathrm{M}, \mathrm{CH}_{3} \mathrm{OH}\right) \quad \lambda_{\max }(\varepsilon)=315 \mathrm{~nm}$ $\left(24 \times 10^{5} \mathrm{M}^{-1} \mathrm{~cm}^{-1}\right)$.

X-ray Data Collection and Structure Refinements

Crystal data of $\mathbf{2}$ were collected on a Bruker SMART APEX CCD diffractometer using the SMART/SAINT software [9]. X-ray quality crystal was mounted on a glass fiber with traces of viscous oil. Intensity data were collected using graphite-monochromatized Mo-K $\alpha$ radiation $(0.7107 \AA)$ at $150 \mathrm{~K}$. The structures were solved by direct methods using the SHELX-97 [10-12] incorporated in WinGX [13-15]. Empirical absorption corrections were applied with SADABS [16]. All non-hydrogen atoms were refined with anisotropic displacement coefficients. Hydrogen atoms were assigned isotropic displacement coefficients, $U(\mathrm{H})=1.2 U(\mathrm{C})$ or $1.5 U$ (C-methyl), and their coordinates were allowed to ride on their respective carbons.

Fluorescence Sensing Study

A $2 \mathrm{~mL}$ stock solution $\left(9.0 \times 10^{-5} \mathrm{M}\right)$ of rectangle 2 in $\mathrm{CH}_{3} \mathrm{OH}$ was placed in a quartz cell of $1 \mathrm{~cm}$ width and nitroaromatic stock solution $\left(1.0 \times 10^{-3} \mathrm{M}\right)$ in $\mathrm{CHCl}_{3}$ was added into it in an incremental fashion. The whole titration experiment was carried out at 298 K. For all measurements rectangle 2 was excited at $\lambda_{\text {ex }}=310 \mathrm{~nm}$ and their corresponding emission wavelengths were monitored from $\lambda_{\mathrm{em}}=310 \mathrm{~nm}$ onwards. For all the measurements both excitation and emission slit widths were $5 \mathrm{~nm}$. Analysis of the normalized fluorescence emission intensity $\left(\mathrm{I}_{0} / \mathrm{I}\right)$ as a function of increasing quencher concentration [Q] was well described by the Stern-Volmer equation $I_{0} / I=1$ $+\mathrm{K}_{\mathrm{SV}}[\mathrm{Q}]$. The Stern-Volmer binding constant $\left(\mathrm{K}_{\mathrm{SV}}\right)$ was calculated from the slope of the Stern-Volmer plot.

\section{Results and Discussion}

Synthesis and Characterization of Rectangle (2)

As shown in Scheme 1, the synthesis of chloro-bridged cationic molecular rectangle $\mathbf{2}$ was accomplished in a
Scheme 1 Schematic representation of the formation of chloro-bridged molecular rectangle 2
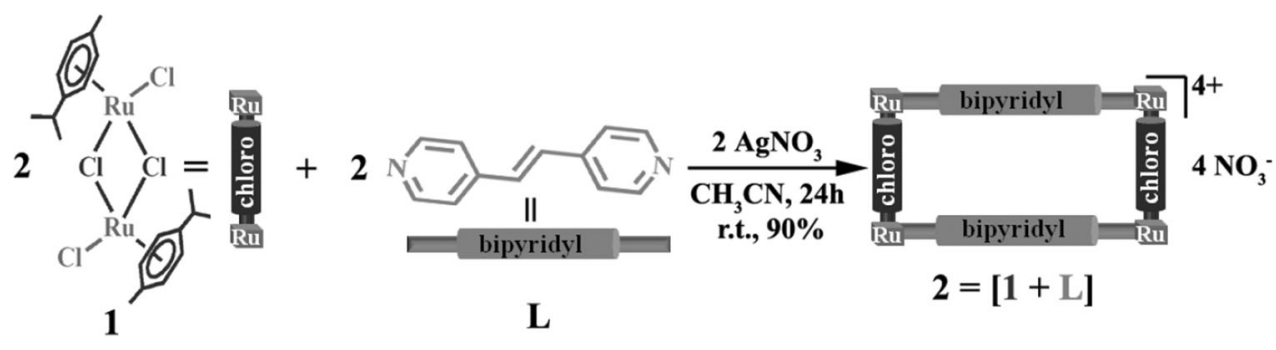
single step by the reaction of a chloro-bridged $\mathrm{Ru}_{2}^{\mathrm{II}}$ acceptor (1) with dipyridyl donor $(\mathbf{L})$ in presence of 2 eq. $\mathrm{AgNO}_{3}$.

Upon addition of the solid dipyridyl donor $\mathbf{L}$ to a clear yellow filtrate, which was obtained from the reaction of $\mathbf{1}$ and $\mathrm{AgNO}_{3}$ in a 1:2 molar ratio in $\mathrm{CH}_{3} \mathrm{CN}$ at room temperature, and subsequent stirring at room temperature for $24 \mathrm{~h}$ resulted in the formation $[2+2]$ self-assembled molecular rectangle 2 in good yield $(90 \%)$. The resulted macrocycle is highly soluble in common organic solvents like $\mathrm{CH}_{3} \mathrm{OH}, \mathrm{CH}_{3} \mathrm{CN}, \mathrm{CH}_{3} \mathrm{NO}_{2}, \mathrm{CHCl}_{3}$ and $\mathrm{CH}_{2} \mathrm{Cl}_{2}$. Formation of this rectangle was initially characterized IR, ${ }^{1} \mathrm{H}$ NMR and molecular structure of $\mathbf{2}$ was determined by single crystal X-ray diffraction analysis. The infra-red spectra of $\mathbf{2}$ is dominated by stretching vibrations of ethylenic $\mathrm{C}=\mathrm{C}$ double bond centered at $\mathrm{v}=1,607 \mathrm{~cm}^{-1}$ is slightly red-shifted $\left(\sim 13 \mathrm{~cm}^{-1}\right)$ compared to free donor $\left(\mathbf{L} ; v=1,594 \mathrm{~cm}^{-1}\right)$, presumably due to the ligand-metal coordination (Fig. 1) [17].

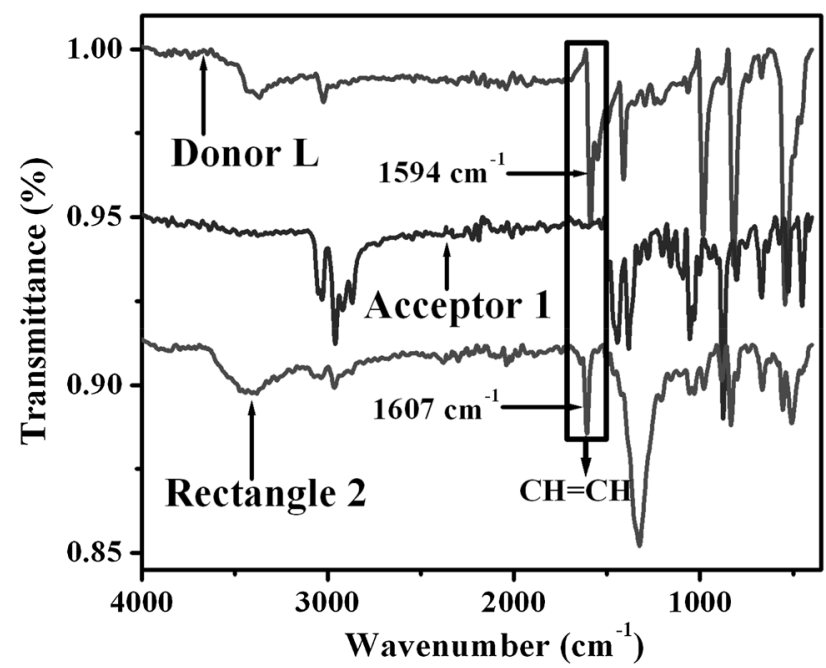

Fig. 1 Infra-red spectra of acceptor (1), donor (L) and rectangle (2)
The ${ }^{1} \mathrm{H}$ NMR spectra of 2 showed a sharp singlet at $\delta=7.51 \mathrm{ppm}$ corresponding to the ethylenic $(\mathrm{HC}=\mathrm{CH})$ protons, two sharp doublets in the range of $\delta=8.34-7.55 \mathrm{ppm}$ are corresponding to $\mathrm{H}_{\alpha}, \mathrm{H}_{\beta}$ protons of dipyridyl donor and two doublets at $\delta=6.00-5.86 \mathrm{ppm}$ due to capped $p$-cymene moieties (Fig. 2). Notably, the proton signals of pyridyl moiety of linker $\mathbf{L}$ exhibited little downfield shifts due to the loss of electron density upon coordination of the pyridine- $\mathrm{N}$ to the $\mathrm{Ru}(\mathrm{II})$ metal centers.

\section{X-ray Crystal Structure of Rectangle (2)}

Suitable single crystals of $\mathbf{2}$ for diffraction analysis were obtained by slow vapor diffusion of diethylether into a concentrated methanolic solution of $\mathbf{2}$ at room temperature. A ball \& stick representation of $\mathbf{2}$ with atom numbering is depicted in Fig. 3. Table 1 summarizes the crystallographic data and refinement parameters, while the selected bond parameters (bond length $\&$ bond angle) are assembled in the Table S1 (Supporting Information). Molecular structures of 2 adopts a tetranuclear cationic rectangular geometry composed of $\left[(p \text {-cymene })_{4} \mathrm{Ru}_{4}(\mu-\mathrm{Cl})_{4}(\mu-1,2-\right.$ bis(4-pyridyl)ethylene $\left.)_{2}\right]^{4+} .4 \mathrm{NO}_{3}{ }^{-}$. By assuming that capped $p$-cymene occupies three coordination sites, each $\mathrm{Ru}$ metal centers adopts a three-legged piano-stool conformation, which is a six-coordinated quasi-octahedral geometry. Each Ru center is coordinated to one nitrogen atom of trans-1,2-bis(4-pyridyl)ethylene linker and two bridged chlorides resulting in a tetranuclear rectangular geometry with the overall dimension of $3.24 \AA \times 13.51 \AA$. The average $\mathrm{Ru}-\mathrm{Cl} / \mathrm{N}$ bond distances ranges between 2.095 and $2.114 \AA$. The observed bridging $\mathrm{Ru}-\mathrm{Cl}$ average distance $(2.09 \AA)$ is shorter than that observed in other areneruthenium complexes possessing bridging $\mathrm{Cl}$ ligands [18]. Moreover, the two dipyridyl donor linkers are almost parallel having strong $\pi-\pi$ interactions $(3.52 \AA$ ), whereas bridged-chlorine atoms are squeezed into acquire a quasi-
Fig. $2{ }^{1} \mathrm{H}$ NMR spectra of the rectangle 2 recorded in $\mathrm{CD}_{3} \mathrm{OD}$ with peak assignments

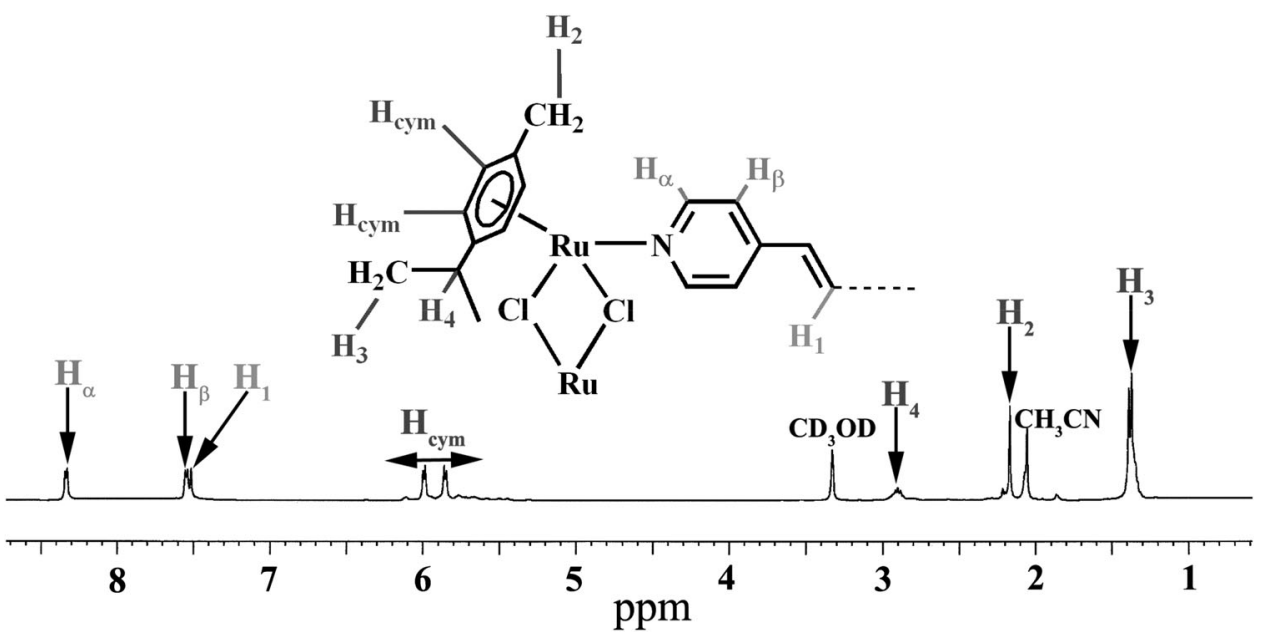


Fig. 3 Ball \& stick (above) and CPK (below) views of rectangle 2 with atom numbering. All hydrogen atoms, counter anions, isopropyl and methyl groups of $p$-cymene unit are omitted for the sake of clarity

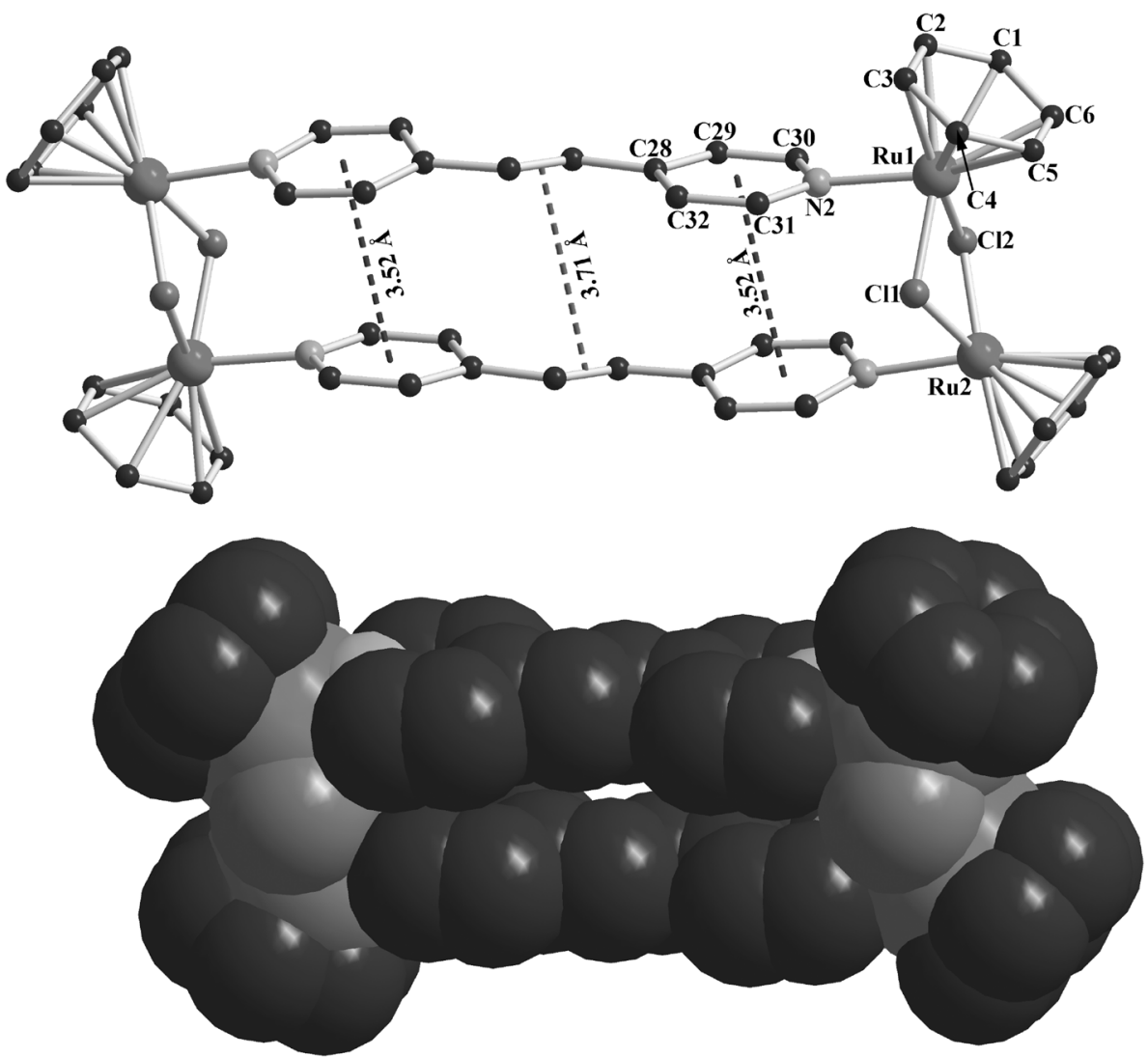

Table 1 Crystallographic data and refinement parameters for rectangle 2

\begin{tabular}{ll}
\hline Complex & $\mathbf{2}$ \\
\hline Empirical formula & $\mathrm{C}_{64} \mathrm{H}_{76} \mathrm{Cl}_{4} \mathrm{~N}_{8} \mathrm{O}_{14} \mathrm{Ru}_{4}$ \\
Formula weight & $1,727.41$ \\
Crystal system & monoclinic \\
Space group & $P 21 / \mathrm{C}$ \\
$\mathrm{T}, \mathrm{K}$ & 150 \\
$\lambda(\mathrm{Mo} \mathrm{K} \alpha), \AA$ & 0.71073 \\
$\mathrm{a}, \AA$ & $14.2684(17)$ \\
$\mathrm{b}, \AA$ & $9.4267(11)$ \\
$\mathrm{c}, \AA$ & $24.513(3)$ \\
$\alpha,{ }^{\circ}$ & 90 \\
$\beta,{ }^{\circ}$ & $91.621(2)$ \\
$\gamma,{ }^{\circ}$ & 90 \\
$\mathrm{~V}, \AA^{3}$ & $3,295.8(7)$ \\
$\mathrm{Z}$ & 2 \\
$\rho_{\text {calcd }}, \mathrm{Mg} / \mathrm{m}^{3}$ & 1.741 \\
$\mu, \mathrm{mm}^{-1}$ & 1.133 \\
$\mathrm{GOF}^{\mathrm{a}}$ & 1.126 \\
$\mathrm{R} 1^{\mathrm{b}}[\mathrm{I}>2 \sigma(\mathrm{I})]$ & $0.0814(4,763)$ \\
$\mathrm{wR}^{\mathrm{c}}[\mathrm{I}>2 \sigma(\mathrm{I})]$ & $0.2086(6,484)$ \\
\hline
\end{tabular}

${ }^{\mathrm{a}} \mathrm{GOF}=\left\{\Sigma\left[w\left(F_{0}^{2}-F_{c}^{2}\right)^{2}\right] /(n-p)\right\}^{1 / 2}$, where $n$ and $p$ denotes the number of data points and the number of parameters, respectively $\left.\left.{ }_{0}^{2}\right)+2 F_{c}^{2}\right] / 3$

${ }^{\mathrm{b}} \mathrm{R} 1=\left(\Sigma \mathrm{II} F_{0} \mathrm{I}-\mathrm{I} F_{c} \mathrm{II}\right) / \Sigma \mathrm{I} F_{0} \mathrm{I}$

${ }^{\mathrm{c}} \mathrm{wR} 2=\left\{\Sigma \quad\left[w\left(F_{0}^{2}-F_{c}^{2}\right)^{2}\right] / \Sigma\left[w\left(F_{0}^{2}\right)^{2}\right]\right\}^{1 / 2}$, where $w=1 /\left[\sigma^{2}\left(F_{0}^{2}\right)+(a P)^{2}\right.$

$+(b P)]$ and $P=[\max (0, F$ octahedral geometry (Fig. 3). The distance between two ethylenic $\mathrm{C}=\mathrm{C}$ double bonds is $3.71 \AA$ A Further, the solidstate packing of rectangle 2 along crystallographic ' $b$ ' axis results in a porous structure with rectangular-type channels through multiple supramolecular $(\pi-\pi$ and $\mathrm{HC}-\pi)$ interactions between the adjacent macrocycles (Fig. S1, Supplementary Information). Nitrate $\left(\mathrm{NO}_{3}{ }^{-}\right)$counter anions and two water molecules are located outside of the rectangular channel (Fig. S1, Supplementary Information).

\section{Fluorescence Sensing of Nitroaromatic Explosives}

The detection and selective discrimination of trace chemical explosives is very crucial for environmental cleaning and national safety and it is a challenging task in the field of chemical sensors. Substantial efforts have been devoted in the recent past for the development of suitable sensors for chemical explosives [19]. Nitro-substituted chemical compounds like TNT and PA are the principal components in many buried landmines making them a common focus of chemists to design selective sensors for detection [20]. Various methods of nitroaromatic sensing are available (Fig. 4).

Among them the fluorescence sensing method has attracted a special attention due to their high sensitivity and low-cost. In the fluorescence sensing method, the initial intensity of sensor is attenuate in presence of explosive 
<smiles>COc1ccc([N+](=O)[O-])c(O[N+]([O-])([O-])c2ccc(O)c([N+](=O)[O-])c2)c1</smiles>

Fig. 4 Tested nitroaromatics

residues [21]. A vast number of organic/inorganic polymeric and small molecule chemosensors have been designed over the past two decades and demonstrated their sensing ability [22, 23]. However, fluorescence sensor to selectively discriminate the most common explosives such as PA and TNT are known to a lesser extent. Despite of their electron-deficient nature, TNT and PA are differing much in their structural point of view. TNT is a toluene based system whereas PA is a phenolic system. Therefore, one can design a chemosensor with electron-donating functional groups (preferentially electronegative atoms) that binds selectively with $-\mathrm{OH}$ group of PA; thereby it is easy to discriminate PA from TNT. Rectangle $\mathbf{2}$ is composed of trans-1,2-(bis-4-pyridyl)ethylene (L) linkers and chloro-bridged arene-ruthenium building units. Based on the aforesaid consideration, it is expected that $\mathbf{2}$ can selectively discriminate phenolic-nitroaromatics such as PA, DNP and NP from other nitroaromatics (TNT, DNT etc.) possibly via hydrogen bonding interactions. The electronic absorption spectrum (Fig. 5) of 2 in $\mathrm{CH}_{3} \mathrm{OH}$ $(10 \mu \mathrm{M})$ shows a peak at $\lambda=315 \mathrm{~nm}\left(\varepsilon=24 \times 10^{5} \mathrm{M}^{-1}\right.$ $\mathrm{cm}^{-1}$ ), which is tentatively assigned to intra/intermolecular $\pi-\pi^{*}$ transitions/metal-to-ligand charge transfer (MLCT). Rectangle 2 shows moderate emission characteristics in $\mathrm{CH}_{3} \mathrm{OH}(10 \mu \mathrm{M})$ solution (Fig. 5).
To verify sensing propensity of rectangle 2 towards nitroaromatics, we performed fluorescence titration study of 2 with various nitroaromatics (Fig. 4) in $\mathrm{CH}_{3} \mathrm{OH}-\mathrm{CHCl}_{3}$ solution. Upon gradual addition of $\mathrm{PA}$ in $\mathrm{CHCl}_{3}(1.0 \mathrm{mM})$ to a methanolic solution $(10 \mu \mathrm{M})$ of $\mathbf{2}$ at room temperature, the initial fluorescence intensity was quenched rapidly (Fig. 6). Along with the efficient quenching of emission intensity, a new low-energy band at $\lambda=\sim 437 \mathrm{~nm}$ appeared upon increasing concentration of PA. Similar titration of $\mathbf{2}$ with DNP also attenuated the initial emission intensity and two new low-energy bands at $\lambda=419 \mathrm{~nm}$ and $442 \mathrm{~nm}$ were observed upon gradual increasing the concentration (Fig. S2, Supplementary Information). Similar fluorescence titration of $\mathbf{2}$ with NP caused only a significant quenching of emission intensity without any new low-energy band even at high concentration (Fig. 6). In all the cases, an upward curvature (nonlinear) type of SternVolmer plot was obtained from the fluorescence quenching titration profile. According to the Stern-Volmer equation (see experimental section), for the static or dynamic quenching a linear Stern-Volmer plot is expected from the plot of $\mathrm{I}_{0} / \mathrm{I}$ and quencher concentration [Q]. However, the obtained nonlinear plot suggest that the fluorescence quenching of rectangle upon the gradual addition of nitroaromatics follows both static as well as dynamic quenching pathways through charge-transfer complex formation. A significant increase in the absorption intensity of 2 was noticed upon the gradual mixing of $\mathrm{NP}$ in $\mathrm{CHCl}_{3}$ $\left(1.0 \times 10^{-3} \mathrm{M}\right)$ to a methanolic solution of $2\left(9.0 \times 10^{-5}\right.$ M) at room temperature (Fig. S3, Supporting Information). Further, a marked visual color change (light brown to intense yellow) was observed upon mixing of rectangle $\mathbf{2}$ in $\mathrm{CH}_{3} \mathrm{OH}$ with chloroform solution of DNP and PA (Fig. 7). The considerable changes of initial absorption intensity including a sharp visual color change are indicative of the formation of ground state charge transfer (CT) complex and supported that the observed fluorescence quenching of 2 mainly follows the static quenching mechanism via ground-state charge transfer complex formation. Therefore,
Fig. 5 UV-Visible absorption (left) and emission (right) spectra of rectangle 2 in $\mathrm{CH}_{3} \mathrm{OH}$ $(10 \mu \mathrm{M})$ at room temperature
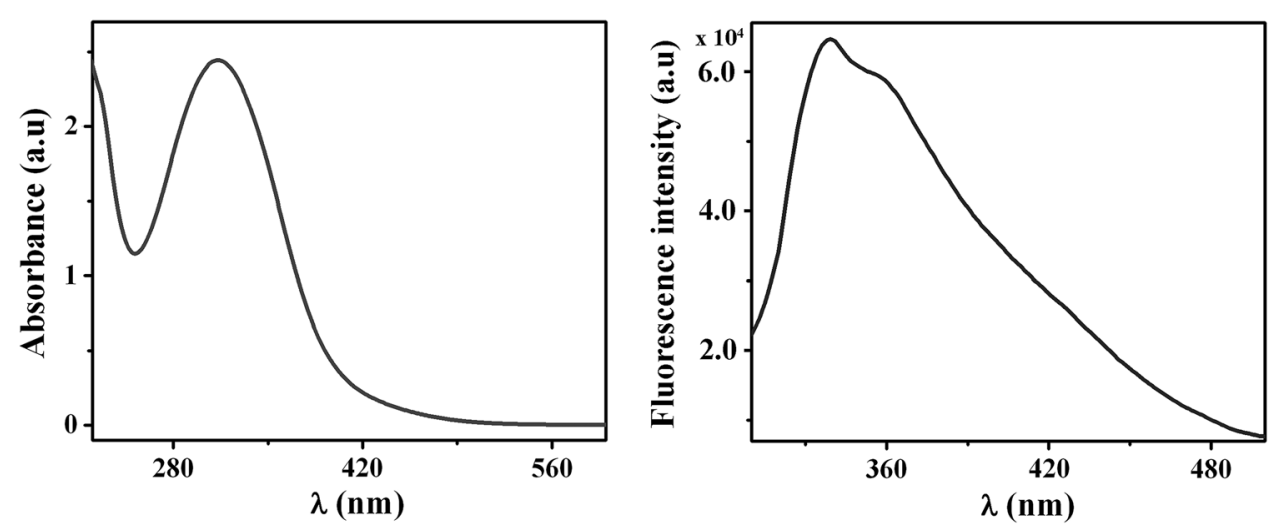
Fig. 6 Changes in fluorescence intensity of rectangle 2 observed upon the titration with NP (top left), PA (bottom left) and their corresponding Stern-Volmer plot (right) monitored at $\lambda=339 \mathrm{~nm}$
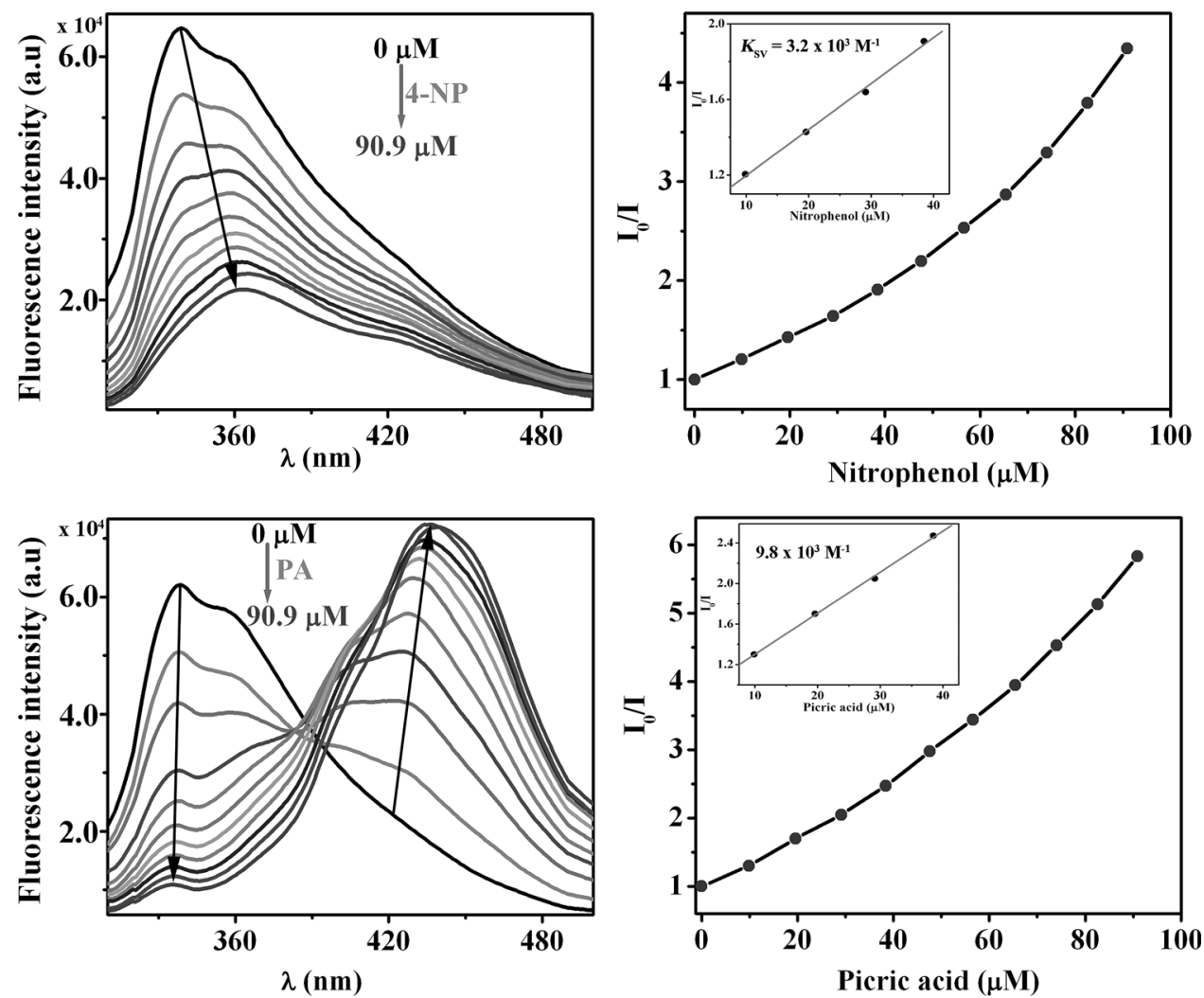
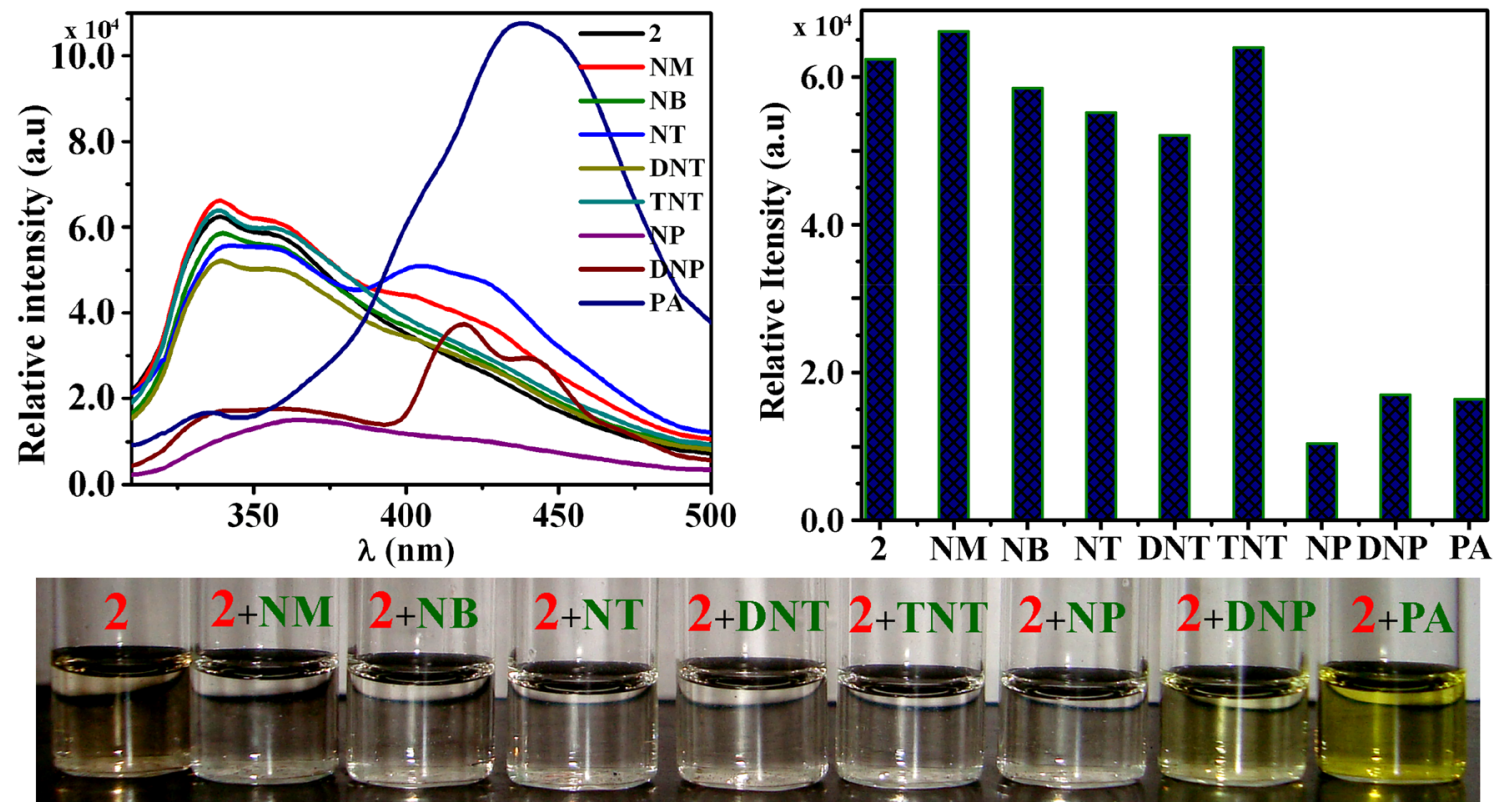

Fig. 7 Relative changes (above left) in the initial fluorescence intensity of 2 upon addition of different nitroaromatics in $\mathrm{CHCl}_{3}-\mathrm{CH}_{3} \mathrm{OH}$ and their corresponding bar spectra (above right) and observed visual color changes in room light (below)

the Stern-Volmer binding constant $K_{\mathrm{SV}}=3.2 \times 10^{3} \mathrm{M}^{-1}$ for NP, $6.4 \times 10^{3} \mathrm{M}^{-1}$ for DNP and $9.8 \times 10^{3} \mathrm{M}^{-1}$ for PA were obtained at low concentration of analytes (Fig. 6 and Fig. S2, Supporting Information).
To corroborate selectivity of rectangle $\mathbf{2}$, we further carried out fluorescence titration of $\mathbf{2}$ with other non-phenolic nitroaromatic (NM, NB, NT, DNT and TNT) under identical spectroscopic conditions and obtained results 
were compared with phenolic nitroaromatics (PA, DNP and NP). As shown in Fig. 7, the tested non-phenolic nitroaromatics elicited almost no fluorescence quenching responses whereas the phenolic nitroaromatic exhibited a significant fluorescence quenching. The possible reason for the high selectivity of $\mathbf{2}$ towards phenolic-analytes is presumably ascribed to the hydrogen bonding interactions between $-\mathrm{OH}$ and bridged $\mathrm{Cl}$ atom.

\section{Conclusion}

In conclusion, we have shown the synthesis of a chlorobridged tetranuclear cationic molecular rectangle 2 via the self-assembly of arene-ruthenium acceptor $\mathbf{1}$ with a symmetrical dipyridyl donor (L) in quantitative yield. Rectangle 2 is fully characterized by ${ }^{1} \mathrm{H}$ NMR, IR and singlecrystal diffraction analysis. Further we have demonstrated the fluorescence quenching based selective sensing of phenolic nitroaromatics from other interfering nitroaromatics. Thus, rectangle $\mathbf{2}$ can be viewed as fluorescence sensor to discriminate PA and TNT.

Acknowledgments P.S.M thanks the Department of Science and Technology (DST), India, for the financial support.

\section{References}

1. Chakrabarty R, Mukherjee PS, Stang PJ (2011) Supramolecular coordination: self-assembly of finite two- and three-dimensional ensembles. Chem Rev 111:6810-6918

2. Ruben M, Lehn JM, Muller P (2006) Addressing metal centres in supramolecular assemblies. Chem Soc Rev 35:1056-1067

3. Shanmugaraju S, Bar AK, Chi KW, Mukherjee PS (2010) Coordination-driven self-assembly of metallamacrocycles via a new $\mathrm{Pt}_{2}^{\mathrm{II}}$ organometallic building block with $90^{\circ}$ geometry and optical sensing of anions. Organometallics 29:2971-2980

4. Shanmugaraju S, Bar AK, Mukherjee PS (2010) Rutheniumoxygen coordination-driven self-assembly of $\mathrm{a} \mathrm{Ru}_{8}^{\mathrm{II}}$ incomplete prism: synthesis, structure, and shape-selective molecular recognition study. Inorg Chem 49:10235-10237

5. Shanmugaraju S, Joshi SA, Mukherjee PS (2011) Self-assembly of metallamacrocycles using a dinuclear organometallic acceptor: synthesis, characterization, and sensing study. Inorg Chem 50:11736-11745

6. Yan H, Suss-Fink G, Neels A, Stoeckli-Evans H (1997) Mono-, di- and tetra-nuclear $p$-cymeneruthenium complexes containing oxalato ligands. J Chem Soc Dalton Trans 22:4345-4350

7. Therrien B (2009) Arene ruthenium cages: boxes full of surprises. Eur J Inorg Chem 17:2445-2453

8. Zelonka RA, Baird MC (1972) Benzene complexes of ruthenium(II). Can J Chem 50:3063-3072

9. SMART/SAINT (2004) Bruker AXS, Inc., Madison, WI

10. Sheldrick GM (1998) SHELX-97, program for the solution and refinement of crystal structures. University of Gottingen, Gottingen

11. Farrugia LJ (2003) WinGX: an integrated system of windows programs for the solution, refinement and analysis for single crystal X-ray diffraction data, version 1.65.04. Department of Chemistry, University of Glasgow, Glasgow

12. Farrugia LJ (1999) WinGX suite for small-molecule singlecrystal crystallography. J Appl Crystallogr 32:837-838

13. Sheldrick GM (1999) SADABS, Bruker nonius area detector scaling and absorption correction, version 205. University of Gottingen, Gottingen

14. Farrugia LJ (1997) ORTEP-3 for Windows, version 1.08. J Appl Crystallogr 30:565

15. Spek AL (1990) PLATON, An integrated tool for the analysis of the results of a single crystal structure determination. Acta Crystallogr A 46:C34

16. Govindaswamy P, Sŭss-Fink G, Therrien B (2007) Self-assembled chloro-bridged (arene)ruthenium metallo-prisms: synthesis and molecular structure of cationic complexes of the type $\left[\mathrm{Ru}_{6}\left(\eta^{6} \text {-arene }\right)_{6}\left(\mu_{3} \text {-tpt- } \kappa \mathrm{N}\right)_{2}(\mu-\mathrm{Cl})_{6}\right]^{6+}(\mathrm{tpt}=2,4,6$-tris $($ pyridinyl)-1,3,5-triazine). Organometallics 26:915-924

17. Therrien B, Ward TR, Pilkington M, Hoffmann C, Gilardoni F, Weber J (1998) Synthesis and reactivity of tethered $\eta^{1}: \eta^{6}$ (phosphinoarene)ruthenium dichlorides. Organometallics 17:330-337

18. Germain ME, Knapp MJ (2009) Optical explosives detection: from color changes to fluorescence turn-on. Chem Soc Rev 38:2543-2555

19. Toal SJ, Trogler WC (2006) Polymer sensors for nitroaromatic explosives detection. J Mater Chem 16:2871-2883

20. Moore DS (2004) Instrumentation for trace detection of high explosives. Rev Sci Instrum 75:2499-2512

21. John H, Sailor MJ, Magde D, Trogler WC (2003) Detection of nitroaromatic explosives based on photoluminescent polymers containing metalloles. J Am Chem Soc 125:3821-3830

22. Shanmugaraju S, Joshi SA, Mukherjee PS (2011) Fluorescence and visual sensing of nitroaromatic explosives using electron rich discrete fluorophores. J Mater Chem 21:9130-9138

23. Shanmugaraju S, Jadhav H, Karthik R, Mukherjee PS (2013) Electron rich supramolecular polymers as fluorescent sensors for nitroaromatics. RSC Adv 3:4940-4950 